\title{
Characterization of Native and Graft Copolymerized Albizia Gums and Their Application as a Flocculant
}

\author{
T. Adeniyi Afolabi and Daniel G. Adekanmi \\ Department of Chemistry, Federal University of Agriculture, Abeokuta, Nigeria \\ Correspondence should be addressed to T. Adeniyi Afolabi; niyiafo@yahoo.com
}

Received 5 April 2017; Accepted 7 May 2017; Published 18 June 2017

Academic Editor: Yves Grohens

Copyright (c) 2017 T. Adeniyi Afolabi and Daniel G. Adekanmi. This is an open access article distributed under the Creative Commons Attribution License, which permits unrestricted use, distribution, and reproduction in any medium, provided the original work is properly cited.

\begin{abstract}
The functional properties and flocculation efficiency of purified Albizia saman (AS) and Albizia glaberrima (AG) gum exudates modified by graft copolymerization with acrylamide were investigated. The grafting efficiency of $A S$ and $A G$ was 54 and $58 \%$, respectively. The cold water-insoluble gel of native $A S$ and $A G$ was 38.23 and $35.55 \%$, which increased to 39.75 and $40.55 \%$ after graft copolymerization. Graft copolymerization of $A S$ and $A G$ gums reduced their oil binding and emulsion capacity from 4.89 and $3.44 \%$ to 3.69 and $2.40 \%$, respectively. The dissolution kinetics of the native gums between 40 and $90^{\circ} \mathrm{C}$ and 0 and 150 min revealed a steady increase in solubility of the native gums from 6.05 to $9.53 \mathrm{~g} / \mathrm{L}(A S)$ and 5.90 to $8.78 \mathrm{~g} / \mathrm{L}(A G)$. The flocculation efficiency of the native $A S$ and $A G$ gums at 50 ppm concentration was 74.30 and $74.73 \%$, which increased to $98.46 \%$ and $98.29 \%$ in the graft copolymerized gums, respectively.
\end{abstract}

\section{Introduction}

The increase in world population has greatly influenced the expansion and sophistication of the industrial growth, with its concomitant environmental hazard. One of these hazards is water pollution by industrial and agricultural waste systems. The generation of wastewater which contains very fine suspended solids, organic and inorganic particles, dissolved solids, metals, and other impurities is harmful to the environment with major health issues in various organisms. These impurities have a very small particle size and rarely settle down; hence their filtration is very difficult and expensive. Among the several traditional and advanced technologies applied for the removal of colloidal particles from wastewater [1], flocculation is one of the most widely used solid-liquid separation process [1-3].

Lee et al. [3] classified flocculants used in wastewater treatments as chemical coagulants/flocculants, natural bioflocculants, and grafted flocculants. The chemical coagulants/ flocculants include coagulants which are inorganic metal salts and flocculants which are synthetic organic polymers. Grafted flocculants (or graft copolymers) include synthetic polymers and natural polymers such as chitosan, cellulose, starch, and gums. The natural bioflocculants are chitosan, cellulose, sodium alginate, tannin, gums, and mucilage.

The presence of residual metal concentration in treated water and poor flocculating efficiency is the major disadvantage of using inorganic coagulants despite their low cost and ease of use [1]. Similarly, lack of biodegradability and dispersion of monomers residue in treated water negate the wide application of organic polymeric flocculants because of its associated health hazards [4]. Hence, biopolymers based flocculants are gaining much interest by researchers because they are biodegradable and environmentally friendly $[1,3]$. One of such biopolymers is gum.

Gums are widely used as flocculants in water treatment because they are nontoxic, biodegradable, and effective [5]. Their efficiency as flocculants is largely dependent on the gum's molecular ability to trap suspended particles to form flocs. Gums are believed to be produced through metabolic activity, as a protective mechanism against pathological conditions or as a consequence of infection on the plant by microorganisms [6]. Gums and other natural flocculants are however needed in large dosage due to their moderate flocculating efficiency and shorter shelf life [3]. Hence, polysaccharides are grafted with synthetic polymers, such as 
acrylamide, to obtain tailor-made grafted flocculants with specialized functions [7].

Extensive studies have been carried out on polysaccharide gums because they are sustainable, biodegradable, and biosafe $[8,9]$. The most utilized gum with diverse industrial application is gum arabic $[9,10]$. The demand for major gums such as gum arabic, guar gum, and xanthan gum for applications in the food, pharmaceutical, and allied industries has led to the concomitant increase in their cost. New inexpensive gum exudates obtained from diverse plants have attracted the attention of researchers for a wide range of industrial applications $[8,9,11,12]$. Hence, the need to search for gums from lesser known and underutilized plants species such as Albizia, which will be economical and readily available, has become expedient.

Albizia (family: Fabaceae; subfamily: Mimosoideae) is a genus of about 150 species of mostly fast growing subtropical and tropical trees and shrubs occurring in Africa, Asia, Australia, and America [13]. Albizia trees are a good source of gums, and its gums have been explored as a suitable substitute for gum arabic as a natural emulsifier for foods and pharmaceuticals [14]. Dabhade et al. [15] reported the extraction of proteinaceous trypsin inhibitor from seeds of Albizia amara and its potentials as an antimicrobial agent. Leaf extracts from $A G$ [16] and Albizia gummifera [17] were investigated for their neuropharmacological and antimicrobial effects, respectively. The phytochemical properties of the roots of $A G$ were investigated [18], while the gums of Albizia stipulata were used in the development of controlled-release tablets in cancer therapeutics [19].

$A S$ and $A G$ are tree crops cultivated mainly for timber production in Nigeria, with huge gum exudates that are usually wasted. From literature search, records of characterization and industrial application of $A S$ and $A G$ are scarce; hence the study of the functional properties and their industrial application as flocculants in waste water treatment may provide an efficient and functionally viable gum with industrial appeal.

\section{Materials and Methods}

2.1. Materials and Gum Purification. Gum exudates from AS and $A G$ were collected at the Federal University of Agriculture, Abeokuta, Nigeria campus. Analar grade ceric ammonium nitrate and acrylamide were used without further purification. Bark-free impure gum exudates from $A S$ and $A G$ were selected and soaked in water overnight, allowing them to hydrate sufficiently. The schematic diagram of the gum purification process is presented in Figure 1.

2.2. Synthesis of Graft Copolymerized Gum. The purified Albizia gums (5g, on dry weight basis) were dissolved in $200 \mathrm{~mL}$ distilled water, and $25 \mathrm{~g}$ of acrylamide (dissolved in $250 \mathrm{~mL}$ water) was added to the dispersion. The suspension was thoroughly mixed for about 10 minutes with a blender and transferred to the reaction vessel, followed by the addition of $2 \mathrm{~g}$ ceric ammonium nitrate. The reaction was allowed to proceed at $65^{\circ} \mathrm{C}$ (using thermostatic water bath) until a gellike mass was obtained. Unreacted acrylamide monomer was removed by the addition of excess acetone and methanol. The gel formed (graft copolymer) was collected, dried, pulverized, and sieved. The percentage grafting (\% G) and percentage grafting efficiency (\% GE) of the synthesized graft copolymers were evaluated:

$$
\begin{aligned}
& \% \mathrm{G} \\
& =\frac{\text { Weight of graft copolymer }- \text { Weight of polysaccharide }}{\text { Weight of gum }} \\
& \times 100 \text {, } \\
& \text { \% GE } \\
& =\frac{\text { Weight of graft copolymer }- \text { Weight of gum }}{\text { Weight of monomer }} \times 100 \text {. }
\end{aligned}
$$

2.3. FTIR Spectroscopy. The grafting reaction was confirmed by FTIR. The FTIR spectra of the native and acrylamide grafted $A S$ and $A G$ gum samples (using $\mathrm{KBr}$ pellets) were obtained with the aid of FTIR spectrometer (Nicolet MagnaIR 750, series II, Thermo Scientific, Portsmouth, NH, USA) at 400 to $4000 \mathrm{~cm}^{-1}$.

2.4. Proximate Composition. The AACC (2000) method was used in determining the ash content, fat (ether extract), and crude fiber of the gum samples. The bulk and tapped density determined gravimetrically was used to calculate the compressibility index, that is, Carr's index (see (3)). Hausner's ratio measures the cohesiveness of the exudate gum powder and was calculated using (4) [20].

$$
\begin{aligned}
\text { Carr's Index }= & \frac{\text { Bulk density }- \text { Tapped density }}{\text { Bulk density }} \\
& \times 100, \\
\text { Hausner ratio }= & \frac{\text { Tapped Density }}{\text { Bulk Density }} .
\end{aligned}
$$

The oil binding capacity of the gum was determined gravimetrically using the method of Okezie and Bello [21]. The concentration of five minerals (sodium, manganese, lead, calcium, and and magnesium) was determined using an atomic absorption spectrophotometer AAS (Perkin-Elmer 305B).

2.5. Emulsion Capacity. The gum sample $(0.25 \mathrm{~g})$ was blended with $10 \mathrm{~mL}$ of distilled water at room temperature for 30 seconds. After complete dispersion, $10 \mathrm{~mL}$ of oil was added and blended for 5 minutes. The mixture was then quantitatively transferred to a centrifuge tube and centrifuged at $3000 \mathrm{rpm}$ for 5 minutes. The volume of oil separated from the sample after centrifugation was read directly from the tube. 


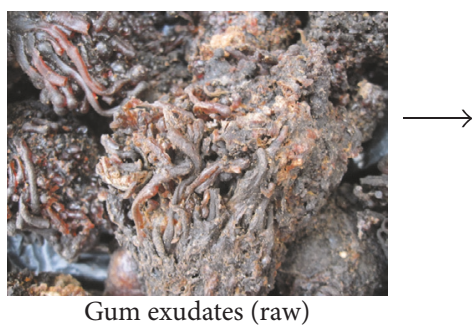

Gum exudates (raw)

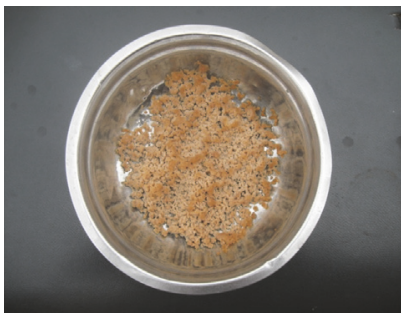

Pure Albizia saman gum after precipitation, washing, and drying

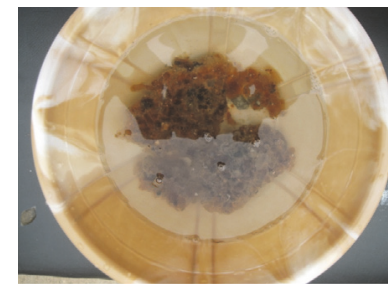

The impure bark-free exudates were soaked in water

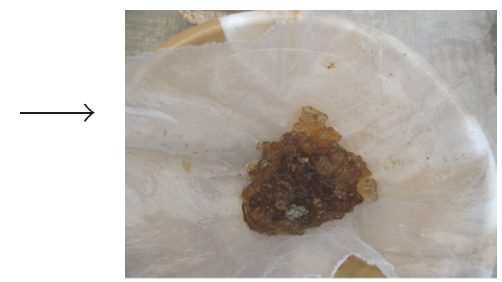

The soaked gum exudates were sieved

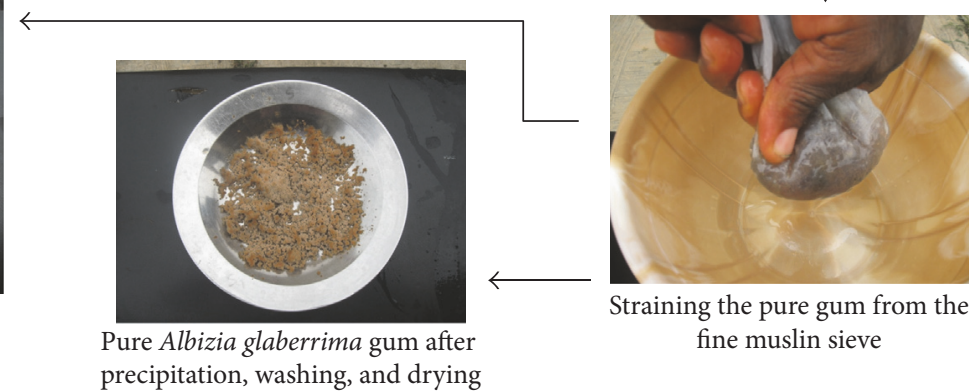

FIgURE 1: Schematic diagram of the Albizia gum's purification.

Emulsification capacity, EC, expressed as mL of oil emulsified by $1 \mathrm{~g}$ samples, was calculated using

$$
\begin{aligned}
& \text { EC } \\
& =\frac{\text { Height of emulsified layer }}{\text { Height of the whole solution in the centrifuge tube }} \\
& \quad \times 100 .
\end{aligned}
$$

\subsection{Cold and Hot Water-Insoluble Gel. A mixture of $1 \mathrm{~g}$ gum} sample and $100 \mathrm{~cm}^{3}$ distilled water was thoroughly mixed for 1 hour. The mixture was then centrifuged at $1200 \mathrm{rpm}$ for 15 minutes and the clear supernatant liquid discarded. The insoluble fraction was washed by adding distilled water and stirring for 3 minutes and recentrifuged at $1200 \mathrm{rpm}$ for 15 minutes. This procedure was repeated four times, before transferring the insoluble fraction into a preweighed porcelain dish. The insoluble fraction was dried in an oven for 12 hours at $105^{\circ} \mathrm{C}$, cooled in a desiccator, and weighed. The difference in weight gives the cold water-insoluble gel (CWIG).

The hot water-insoluble gel (HWIG) determination was carried out by stirring $1 \mathrm{~g}$ of gum in $100 \mathrm{~mL}$ of distilled water for 30 minutes and heating the mixture in a water bath at $95^{\circ} \mathrm{C}$ for 1 hour; the mixture was allowed to stand at room temperature for 4 hours. Separation and determination of the HWIG were carried out as described for CWIG.

2.7. Intrinsic Viscosity. The specific viscosity of the $1 \%$ gum solutions (native and graft copolymerized $A S$ and $A G$ ) was measured with the Brookfield viscometer at 50,60, and $100 \mathrm{rpm}$ and calculated as follows:

$$
\begin{aligned}
\eta_{\text {sp }} & =\eta_{\text {rel }}-1, \\
\eta_{\text {red }} & =\frac{\eta_{\text {sp }}}{C}, \\
\eta_{\text {inh }} & =\frac{\ln \left(\eta_{\text {rel }}\right)}{C} .
\end{aligned}
$$

From the time of flow of polymer solutions $(t)$ and that of the solvent ( $t_{o}$, for distilled water), relative viscosity $\left(\eta_{\text {rel }}=t / t_{o}\right)$ was obtained. The reduced viscosity $\left(\eta_{\text {red }}\right)$ and the inherent viscosity $\left(\eta_{\text {inh }}\right)$ were simultaneously plotted against concentration. " $C$ " represents polymer concentration in g/dL. The intrinsic viscosity was obtained from the point of the intersection after extrapolation of two plots (i.e., $\eta_{\text {red }}$ versus $C$ and $\eta_{\text {inh }}$ versus $C$ ) to zero concentration [22].

2.8. Solubility Capacity. A $1 \%$ gum solution $(2.5 \mathrm{~g}$ of gum in $250 \mathrm{~cm}^{3}$ of water) was vigorously shaken in a thermostatically controlled water bath at $30^{\circ} \mathrm{C}$ for specified time interval $(0$, $30,60,90,120$, or 150 minutes). Then $20 \mathrm{~cm}^{3}$ is drawn out, allowed to cool, and centrifuged at $3000 \mathrm{rpm}$ for 10 minutes. Aliquots $\left(10 \mathrm{~cm}^{3}\right)$ of the supernatant were dried to constant weight at $105^{\circ} \mathrm{C}$ to determine the mass of the gum dissolved. The above experiment was repeated at 40,50,60, 70, and $80^{\circ} \mathrm{C}$.

2.9. Flocculation Study. The flocculation test was done using the modified method of Rani et al. [22]. $100 \mathrm{~mL}$ of $0.25 \%$ Kaolin suspension was added to $10 \mathrm{ppm}$ of the flocculant (native and acrylamide grafted gums). The suspension was 
TABLE 1: Physicochemical properties of native (ASN) and graft copolymerized (ASG) Albizia saman gums and native (AGN) and graft copolymerized (AGG) Albizia glaberrima gums.

\begin{tabular}{|c|c|c|c|c|}
\hline Parameter & ASN & ASG & AGN & AGG \\
\hline Moisture content (\%) & $10.89 \pm 0.01$ & - & $9.91 \pm 0.02$ & - \\
\hline Crude fibre (g/100 g) & $8.59 \pm 0.04$ & - & $9.57 \pm 0.02$ & - \\
\hline Ether extract (g/100 g) & $9.81 \pm 0.01$ & - & $8.01 \pm 0.02$ & - \\
\hline Ash content $(\mathrm{g} / 100 \mathrm{~g})$ & $7.87 \pm 0.02$ & - & $8.60 \pm 0.01$ & - \\
\hline Bulk density $\left(\mathrm{g} / \mathrm{cm}^{3}\right)$ & $0.710 \pm 0.01$ & $0.662 \pm 0.07$ & $0.738 \pm 0.07$ & $0.694 \pm 0.04$ \\
\hline Tapped density $\left(\mathrm{g} / \mathrm{cm}^{3}\right)$ & $0.835 \pm 0.04$ & $0.740 \pm 0.04$ & $0.870 \pm 0.04$ & $0.782 \pm 0.11$ \\
\hline Carr's index & $17.535 \pm 0.06$ & $11.005 \pm 0.07$ & $17.555 \pm 0.18$ & $9.480 \pm 0.11$ \\
\hline Hausner's ratio & $1.176 \pm 0.01$ & $1.117 \pm 0.01$ & $1.179 \pm 0.02$ & $1.127 \pm 0.13$ \\
\hline${ }^{\mathrm{a}} \mathrm{CWIG}(\%)$ & $40.23 \pm 2.47$ & $39.75 \pm 0.95$ & $35.55 \pm 1.34$ & $40.55 \pm 0.14$ \\
\hline${ }^{\mathrm{b}} \mathrm{HWIG}(\%)$ & $8.00 \pm 1.41$ & $14.23 \pm 1.11$ & $10.96 \pm 0.08$ & $15.00 \pm 0.07$ \\
\hline${ }^{\mathrm{c}} \mathrm{OBC}(\mathrm{g})$ & $4.89 \pm 0.03$ & $3.69 \pm 0.13$ & $3.44 \pm 0.00$ & $2.40 \pm 0.06$ \\
\hline${ }^{\mathrm{d}} \mathrm{EC}(\%)$ & $40.00 \pm 0.00$ & $30.09 \pm 0.16$ & $48.58 \pm 0.81$ & $19.88 \pm 0.18$ \\
\hline Intrinsic viscosity $(\mathrm{cP})$ & $0.78 \pm 0.23$ & $1.29 \pm 0.94$ & $1.11 \pm 0.85$ & $1.74 \pm 1.33$ \\
\hline Grafting (\%) & $550.00 \pm 0.04$ & $543.00 \pm 0.08$ & - & - \\
\hline Grafting yield (\%) & $54.00 \pm 0.06$ & $58.00 \pm 0.02$ & - & - \\
\hline Grafting efficiency (\%) & $110.00 \pm 0.05$ & $108.00 \pm 0.07$ & - & - \\
\hline
\end{tabular}

${ }^{\mathrm{a}} \mathrm{CWIG}$, cold water insoluble gel; ${ }^{\mathrm{b}} \mathrm{HWIG}$, hot water insoluble gel; ${ }^{\mathrm{c}} \mathrm{OBC}$, oil binding capacity; ${ }^{\mathrm{d}} \mathrm{EC}$, emulsion capacity.

stirred at $75 \mathrm{rpm}$ for 3 minutes and $25 \mathrm{rpm}$ for 7 minutes and then allowed to settle for 10 minutes. The absorbance of the supernatant liquids was measured with a UV-Visible spectrophotometer at $600 \mathrm{~nm}$. Low absorbance value is indicative of good flocculation efficacy. The procedure was repeated for 30 and 50 ppm of the flocculants.

2.10. Metal Ion Sorption. Metal ion sorption was carried out by stirring $30 \mathrm{ppm}$ ( $3 \mathrm{mg}$ of gum in $100 \mathrm{~mL}$ of water) of the native and grafted gums and $100 \mathrm{~mL}$ solution containing $180 \mathrm{ppm}$ of nickel ion $\left(40 \mathrm{mg}\right.$ of $\mathrm{Ni}_{2} \mathrm{SO}_{4} \cdot 6 \mathrm{H}_{2} \mathrm{O}$ in $100 \mathrm{~mL}$ of water) for 20 minutes, which was filtered, and its concentrations were determined with AAS. The metal ion concentration of the filtrate and its retention capacity were determined using (7) and (8), respectively [22].

Metal ion uptake (\%)

$$
\begin{aligned}
= & \frac{\text { Initial conc. of metal ion }- \text { final conc. of metal ion }}{\text { Initial conc. of ion }} \\
& \times 100 \%,
\end{aligned}
$$

Retention Capacity (ppm/mg)

$$
=\frac{\text { Initial conc of metal ion }- \text { final conc of metal ion }}{\text { Weight of dry polymer }} \text {. }
$$

where molar mass of $\mathrm{Ni}_{2} \mathrm{SO}_{4} \cdot 6 \mathrm{H}_{2} \mathrm{O}$ and $\mathrm{Ni}$ is $262.85 \mathrm{~g} / \mathrm{mol}$ and $58.7 \mathrm{~g} / \mathrm{mol}$, respectively, and conc. is the concentration.

2.11. Statistical Analysis. All determinations were carried out in triplicate and result was reported as the mean \pm standard deviation. The swelling and solubility profile were subjected to one-way analysis of variance (ANOVA) using SPSS (Version 16.0 software) to investigate the effect of $\mathrm{pH}$ and
TABLE 2: The mineral composition of native Albizia saman (ASN) and Albizia glaberrima (AGN) gums.

\begin{tabular}{lcc}
\hline Minerals & ASN & AGN \\
\hline Calcium $(\mathrm{ppm})$ & 64087 & 99394 \\
Magnesium $(\mathrm{ppm})$ & 835.52 & 964.68 \\
Sodium $(\mathrm{ppm})$ & 57842 & 50436 \\
Lead $(\mathrm{ppm})$ & 43.82 & 42.52 \\
\hline
\end{tabular}

temperature on starch samples. The Shapiro-Wilk test of normality and Levene's tests of homogenous variance were carried out to assess the assumptions of ANOVA in order to validate the results.

\section{Result and Discussion}

3.1. Chemical Composition. The physicochemical characteristics of the Albizia gums were presented in Table 1. The grafting efficiency of $A S(110 \%)$ and $A G(108 \%)$ was similar to that reported for gum ghatti using microwave assisted synthesis (Rani et al., 2012). The $10.89 \%$ and $9.9 \%$ moisture contents of $A S$ and $A G$ gums, respectively, are within the specification limit of $\leq 20 \%$ for food and pharmaceutical applications [23]. Moisture content determines the storage conditions of materials and the pharmacopeia limit for moisture contents of natural gums is $\leq 15.0 \%$ [24]. The moisture content of $A S$ and $A G$ gums was at par with that reported for xanthan gum and gum arabic but lower than that reported for other Albizia species $[25,26]$. The $7.87 \%$ and $8.60 \%$ ash content of $A S$ and $A G$, respectively, which is higher than that of most commercial gums (Table 2), is indicative of the high mineral content of the gums [25-27]. 


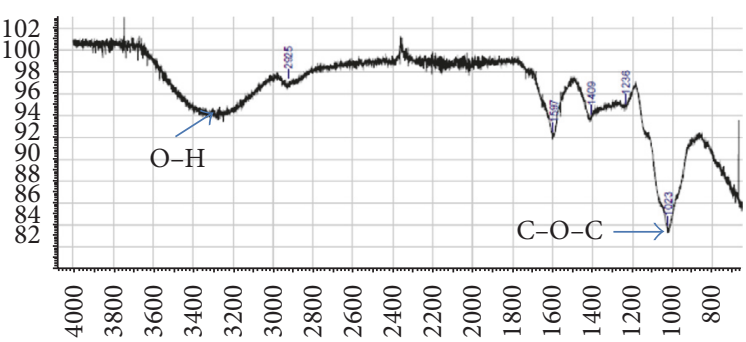

(a) ASN

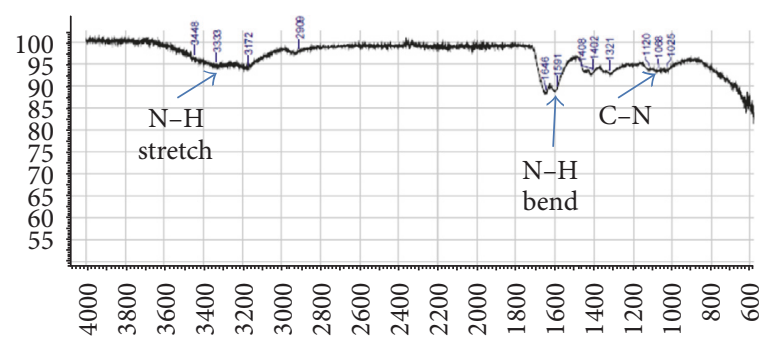

(b) ASG

FIGURE 2: FTIR spectrum of native (ASN) and graft copolymerized (ASG) Albizia saman gums.

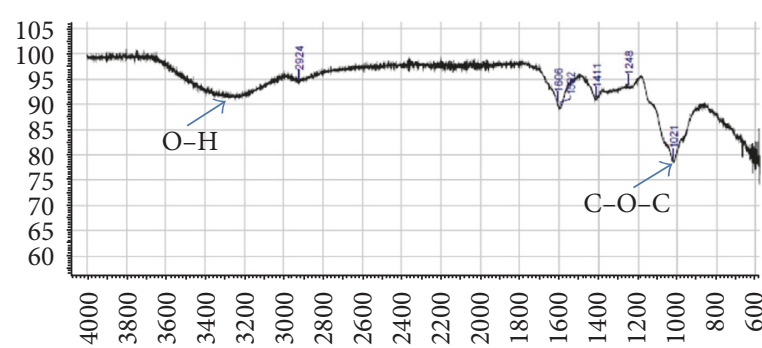

(a) AGN

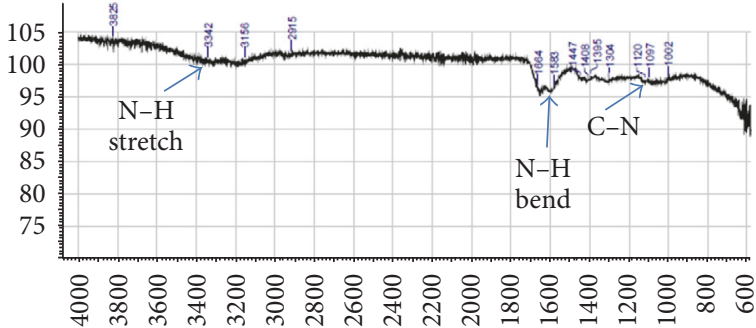

(b) AGG

FIGURE 3: FTIR spectrum of native (AGN) and graft copolymerized (AGG) Albizia glaberrima gums.

The CWIG of $A S$ and $A G(40.23 \%$ and $35.55 \%)$ rapidly decreased in hot water to $8.00 \%$ and $10.96 \%$ (HWIG), respectively. The insoluble gel values observed for $A S$ and $A G$ were higher than that reported for other Albizia species $[25,26]$. Gums are a complex mixture of polysaccharide with soluble and insoluble fractions; however, the quality of a gum is dependent on the soluble fraction [25].

The emulsifying and oil binding capacity of the $A G$ gum was higher than that of $A S$ (Table 1). Also, the emulsifying capacities of the modified gums were lower than their corresponding native gums. This can be associated with a decrease in percentage protein content due to the presence of acrylamide graft, which probably solubilizes the protein. Polysaccharide contains a small amount of strongly hydrophobic protein component bonded to the polysaccharides [28]. These hydrophobic protein components can adsorb at oilwater interfaces to form stabilizing layers around oil droplets [29]. Hence, the oil binding and emulsifying capacity could be associated with the amount of protein in the polysaccharide.

The bulk density $\left(0.710\right.$ and $\left.0.738 \mathrm{~g} / \mathrm{cm}^{3}\right)$ of $A S$ and $A G$ (Table 1) is comparable with the $0.721 \mathrm{~g} / \mathrm{cm}^{3}$ reported for badam gum [30] but higher than the value of $0.564 \mathrm{~g} / \mathrm{cm}^{3}$ for dioclea gum [31] and $0.500 \mathrm{~g} / \mathrm{cm}^{3}$ and $0.600 \mathrm{~g} / \mathrm{cm}^{3}$ for gum arabic and almond gum [27]. The bulk and tapped densities reduced after graft copolymerization of the gums. The bulk and tapped densities quantify the packing arrangement of the particles of a material and its compaction behavior. The powder flow property is important in the consideration of polysaccharide for industrial use [32]. The flowability of powders can be predicted by its compressibility index (expressed as Carr's index). Compressibility index greater than 26 indicates poor flowability; also, low compressibility index is synonymous with excellent flowability $[27,33]$. The 17.535 and 17.555 Carr's index of the Albizia gums which reduced after graft copolymerization is indicative of the gum's excellent flowability.

The intrinsic viscosities of the native gums increased from 0.78 and $1.29 \%$ for $A S$ and $A G$ gums to 1.11 and $1.74 \%$ after graft copolymerization of the gums, respectively (Table 1 ). $A G$ has a higher intrinsic viscosity (higher molecular weight) than AS. An important property of hydrocolloid is their viscosity which exists due to hydrogen bonding between and within segments of the molecules and also with water molecules. Gums have the ability to influence water many times their own volume significantly. The intrinsic viscosity (which is directly related to molecular weight) increased in the graft copolymerized gums.

The FTIR spectra of the native and grafted copolymerized (modified) $A S$ and $A G$ were presented in Figures 2 and 3, respectively. The spectra of the native gums have broadband around $\mathrm{OH}$ band in the $3400-3200 \mathrm{~cm}^{-1}$ range indicating the $\mathrm{OH}$ functional group and a peak around $1028-1022 \mathrm{~cm}^{-1}$ indicating the $\mathrm{C}-\mathrm{O}-\mathrm{C}$ functional group. In addition to the above bands, the spectra of the modified gums both have bands for $\mathrm{N}-\mathrm{H}$ stretch around $3342-3333 \mathrm{~cm}^{-1}$ and for $\mathrm{C}-\mathrm{N}$ around $1097-1088 \mathrm{~cm}^{-1}$.

The grafted copolymerized gums in addition to being lighter in colour had tougher texture compared with the native gums, which could be as a result of stronger covalent bonds (amide linkage). This is corroborated by the peaks around $1646 \mathrm{~cm}^{-1}$ (ASG) and $1664 \mathrm{~cm}^{-1}$ (AGG) in the spectra which is indicative of presence of amide (Figures 2 and 3). 
TABLE 3: The effect of temperature on the solubility of native (ASN) and graft copolymerized (ASG) Albizia saman gums and native (AGN) and graft copolymerized (AGG) Albizia glaberrima gums over time.

\begin{tabular}{|c|c|c|c|c|c|c|}
\hline \multirow{2}{*}{ Gum } & \multirow{2}{*}{ Time (min) } & \multicolumn{5}{|c|}{ Temperature } \\
\hline & & $40^{\circ} \mathrm{C}$ & $50^{\circ} \mathrm{C}$ & $60^{\circ} \mathrm{C}$ & $70^{\circ} \mathrm{C}$ & $80^{\circ} \mathrm{C}$ \\
\hline ASN & 0 & $6.225 \pm 0.040$ & $6.175 \pm 0.040$ & $6.175 \pm 0.04$ & $6.100 \pm 0.07$ & $6.050 \pm 0.07$ \\
\hline ASG & 0 & $5.775 \pm 0.040$ & $5.424 \pm 0.040$ & $5.775 \pm 0.04$ & $5.750 \pm 0.07$ & $5.630 \pm 0.15$ \\
\hline AGN & 0 & $5.900 \pm 0.070$ & $5.850 \pm 0.070$ & $5.875 \pm 0.04$ & $5.875 \pm 0.00$ & $5.875 \pm 0.04$ \\
\hline AGG & 0 & $4.525 \pm 0.040$ & $4.425 \pm 0.040$ & $4.525 \pm 0.04$ & $4.575 \pm 0.11$ & $4.225 \pm 0.04$ \\
\hline ASN & 30 & $6.200 \pm 0.000$ & $6.300 \pm 0.070$ & $7.075 \pm 0.04$ & $7.300 \pm 0.07$ & $8.325 \pm 0.11$ \\
\hline ASG & 30 & $6.075 \pm 0.110$ & $6.100 \pm 0.070$ & $6.125 \pm 0.04$ & $6.075 \pm 0.04$ & $7.075 \pm 0.04$ \\
\hline AGN & 30 & $6.650 \pm 0.070$ & $7.050 \pm 0.000$ & $7.025 \pm 0.04$ & $7.600 \pm 0.07$ & $7.025 \pm 0.04$ \\
\hline AGG & 30 & $5.075 \pm 0.040$ & $5.075 \pm 0.040$ & $5.500 \pm 0.07$ & $5.525 \pm 0.04$ & $5.825 \pm 0.04$ \\
\hline ASN & 60 & $6.225 \pm 0.040$ & $6.625 \pm 0.04$ & $7.375 \pm 0.04$ & $8.125 \pm 0.04$ & $8.925 \pm 0.11$ \\
\hline ASG & 60 & $6.575 \pm 0.040$ & $6.775 \pm 0.04$ & $7.100 \pm 0.00$ & $7.575 \pm 0.04$ & $8.275 \pm 0.04$ \\
\hline AGN & 60 & $7.025 \pm 0.040$ & $7.475 \pm 0.04$ & $8.100 \pm 0.07$ & $8.025 \pm 0.11$ & $8.100 \pm 0.07$ \\
\hline AGG & 60 & $6.050 \pm 0.070$ & $6.525 \pm 0.11$ & $6.625 \pm 0.11$ & $7.775 \pm 0.04$ & $8.100 \pm 0.07$ \\
\hline ASN & 90 & $6.575 \pm 0.110$ & $7.475 \pm 0.04$ & $8.100 \pm 0.07$ & $8.950 \pm 0.07$ & $9.475 \pm 0.04$ \\
\hline ASG & 90 & $6.900 \pm 0.140$ & $7.500 \pm 0.00$ & $7.800 \pm 0.00$ & $8.100 \pm 0.07$ & $8.550 \pm 0.07$ \\
\hline AGN & 90 & $7.800 \pm 0.000$ & $7.950 \pm 0.07$ & $8.325 \pm 0.18$ & $8.200 \pm 0.07$ & $8.325 \pm 0.18$ \\
\hline AGG & 90 & $7.825 \pm 0.040$ & $7.075 \pm 0.04$ & $7.500 \pm 0.14$ & $8.100 \pm 0.07$ & $8.275 \pm 0.04$ \\
\hline ASN & 120 & $7.025 \pm 0.040$ & $7.975 \pm 0.04$ & $8.975 \pm 0.04$ & $9.175 \pm 0.11$ & $9.250 \pm 0.35$ \\
\hline ASG & 120 & $7.775 \pm 0.040$ & $8.075 \pm 0.04$ & $8.300 \pm 0.07$ & $8.575 \pm 0.04$ & $9.200 \pm 0.07$ \\
\hline AGN & 120 & $8.050 \pm 0.070$ & $8.300 \pm 0.00$ & $8.525 \pm 0.04$ & $8.550 \pm 0.07$ & $8.525 \pm 0.04$ \\
\hline AGG & 120 & $7.475 \pm 0.040$ & $8.175 \pm 0.04$ & $8.075 \pm 0.04$ & $8.450 \pm 0.04$ & $8.425 \pm 0.04$ \\
\hline ASN & 150 & $7.575 \pm 0.040$ & $8.025 \pm 0.04$ & $9.075 \pm 0.04$ & $9.300 \pm 0.21$ & $9.525 \pm 0.04$ \\
\hline ASG & 150 & $8.525 \pm 0.040$ & $9.075 \pm 0.04$ & $9.525 \pm 0.04$ & $9.075 \pm 0.04$ & $9.350 \pm 0.04$ \\
\hline AGN & 150 & $8.375 \pm 0.040$ & $8.450 \pm 0.00$ & $8.775 \pm 0.32$ & $8.770 \pm 0.14$ & $8.775 \pm 0.32$ \\
\hline AGG & 150 & $7.975 \pm 0.040$ & $8.450 \pm 0.07$ & $8.575 \pm 0.00$ & $8.770 \pm 0.14$ & $8.670 \pm 0.11$ \\
\hline
\end{tabular}

3.2. Mineral Composition of the Albizia Gums. The mineral composition of the $A S$ and $A G$ is presented in Table 2. The $A S$ and $A G$ gums are richer in calcium and sodium when compared with most of the popular commercial gums such as gum arabic, guar gum, and xanthan gum [25, 26, 34]. Gums contain various metal ions as neutralized atoms; the nature and amount of these constituents depend on the composition of soil upon which the trees grew [35]. Gel formation in certain gums (such as Khaya grandifoliola) has been attributed to calcium ions [36].

The $A S$ and $A G$ gums have the essential cations needed by the body (calcium, sodium, and magnesium), and the metal composition trend is $\mathrm{Ca}>\mathrm{Na} \gg \mathrm{Mg}$ trend which is at par with that reported for other Albizia gums (Anderson and Morisson, 1990). The Albizia gums could be a good gelling agent due to their high calcium content. Lead consumption is dangerous and has a profound effect upon accumulation in the body over a period of time.

3.3. Solubility of the Gums. The effect of temperature (40$80^{\circ} \mathrm{C}$ ) on the solubility profile of the gums is presented in Table 3. As temperature and heating duration increased, the solubility of the gum samples increased. The solubility of the gums at $40^{\circ} \mathrm{C}$ (within $0-150$ minutes) was $6.225-7.575 \mathrm{~g} / \mathrm{L}$ (ASN) and 5.900-8.375 g/L (AGN); this increased steadily as the temperature increased; at $80^{\circ} \mathrm{C}$, it was 6.050-9.525 (ASN) and $5.875-8.775 \mathrm{~g} / \mathrm{L}(\mathrm{AGN})$. The graft copolymerized gum's solubility was lower than that of the native gums but also increased with increase in temperature.

The result of the two-way ANOVA test conducted to investigate the effect of temperature $\left(40,50,60,70\right.$, and $\left.80^{\circ} \mathrm{C}\right)$ and time $(0,30,60,90,120$, and 150 minutes) on the gum's solubility is presented in Table 4 . The Shapiro-Wilk test of normality and Levene's tests of homogenous variance were carried out to validate the assumptions of ANOVA in order to authenticate the results. The Wilk Statistic for the gum samples is $0.921,0.953,0.894$, and 0.872 for ASN, ASG, AGN, and AGG, respectively, and its significance was greater than 0.05 . Levene's test of gum samples was 2.659 with a significance value of 1.64. This result showed that there is a statistically significant interaction between temperature and timing, $F(14,49)=19.013, p=0.129$. This suggests that, at lower temperatures, longer time could enhance solubility. An observation of the main effects shows that the two factors, temperature and time, have statistically significant effect on solubility; temperature: $F(3,49)=68.099, p \leq 0.001$; time: $F(5,49)=$ 424.728, $p \leq 0.001$.

3.4. Flocculation Efficiency of the Gums. The flocculation study in $0.25 \%$ kaolin suspension ("jar test" apparatus) for 
TABLE 4: Analysis of variation (ANOVA) for the solubility of the Albizia gum samples at different temperatures.

\begin{tabular}{lcccr}
\hline Source & Type III sum of squares & Df & Mean square & $F$ \\
\hline Intercept & 15252.898 & 1 & 15252.898 & $9.593 E 4$ \\
Time & 337.653 & 5 & 67.531 & 424.728 \\
Temp & 32.483 & 3 & 10.828 & 68.099 \\
Time $*$ temp & 42.319 & 14 & 3.023 & .000 \\
Error & 10.017 & 49 & .159 & .000 \\
\hline
\end{tabular}

TABLE 5: Flocculation efficiency of native (ASN) and graft copolymerized (ASG) Albizia saman and native (AGN) and graft copolymerized (AGG) Albizia glaberrima gums at different concentrations in $0.25 \%$ kaolin suspension.

\begin{tabular}{lccc}
\hline Gums & & Clarity of kaolin solution $(\%)$ & $50(\mathrm{ppm})$ \\
\hline ASN & $10(\mathrm{ppm})$ & $30(\mathrm{ppm})$ & 74.30 \\
ASG & 60.76 & 68.66 & 98.29 \\
AGN & 96.03 & 98.16 & 74.73 \\
AGG & 60.80 & 70.07 & 98.46 \\
\hline
\end{tabular}

TABLE 6: Ion removal capacity of native (ASN) and graft copolymerized Albizia saman (ASG) and native (AGN) and graft copolymerized (AGG) Albizia glaberrima gums.

\begin{tabular}{lcccc}
\hline Gums & Initial conc. of $\mathrm{Ni}^{2+}(\mathrm{ppm})$ & Final conc. of $\mathrm{Ni}^{2+}(\mathrm{ppm})$ & Metal ion uptake $(\%)$ & Retention capacity $(\mathrm{ppm} / \mathrm{mg})$ \\
\hline ASN & 110.000 & 63.721 & 42.07 & 38.760 \\
ASG & 110.000 & 63.342 & 42.42 & 38.886 \\
AGN & 110.000 & 62.046 & 43.59 & 39.318 \\
AGG & 110.000 & 61.598 & 44.00 & 39.467 \\
\hline
\end{tabular}

10, 30, and $50 \mathrm{ppm}$ dosage was presented in Table 5. The flocculation efficiency of the native gums increased after modifications from $60.76 \%$ (ASN) to $96.03 \%$ (ASG) and $60.80 \%$ (AGN) to $96.38 \%$ (AGG) at $10 \mathrm{ppm}$, with significant increase as the dosage increased. The better flocculation efficacy exhibited by the graft copolymerized Albizia gums (ASG and AGG) compared with their native gums (ASN and AGN) may be due to their higher intrinsic viscosity as evidenced in Table $1[22,37]$. AG gum has better flocculant characteristic in the native and the modified gums compared with $A S$. Branching and molecular weight of polymer chains determine the effectiveness of flocculants [37]. The floc formation is higher in high-molecular-weight branched polysaccharide backbone with flexible grafted polyacrylamide chains.

The ion removal capacity of the native and graft copolymerized $A S$ and $A G$ gums was presented in Table 6. The native and modified $A S$ and $A G$ had high metal ion uptake (42.07-44.00\%) and high retention capacity (38.76$39.47 \mathrm{ppm} / \mathrm{mg}$ ). There was no significant difference in the metal ion uptake and retention capacity of the native and modified Albizia gums. However, the native and modified $A G$ gums have better ion removal and retention capacity than the native and modified $A S$ gum, respectively.

\section{Conclusion}

The $A S$ and $A G$ gums were rich in minerals and contain a higher percentage of insoluble matter compared to most commercial gums. The gums can also be stored for a long time without losing their integrity and have excellent functional properties comparable with those of most commercial gums. The physicochemical properties of the Albizia gums were within the acceptable limits and standards for food pharmaceutical and other industrial applications. A stable graft was formed between acrylamide and the $A S$ and $A G$ gums, with $A G$ gums having higher grafting efficiency. $A G$ gum also has higher flocculation efficiency and ion removal capacity than AS. The modified (acrylamide grafted) Albizia gums are better flocculants than the native gums, with the acrylamide grafted $A G$ gum having the best flocculation efficiency.

\section{Conflicts of Interest}

The authors declare that there are no conflicts of interest regarding the publication of this paper.

\section{References}

[1] R. Yang, H. Li, M. Huang, H. Yang, and A. Li, "A review on chitosan-based flocculants and their applications in water treatment," Water Research, vol. 95, pp. 59-89, 2016.

[2] M. Manafi, P. Manafi, S. Agarwal et al., "Synthesis of nanocomposites from polyacrylamide and graphene oxide: application as flocculants for water purification," Journal of Colloid and Interface Science, vol. 490, pp. 505-510, 2017. 
[3] C. S. Lee, J. Robinson, and M. F. Chong, "A review on application of flocculants in wastewater treatment," Process Safety and Environmental Protection, 2014.

[4] V. H. Dao, N. R. Cameron, and K. Saito, "Synthesis, properties and performance of organic polymers employed in flocculation applications," Polymer Chemistry, vol. 7, no. 1, pp. 11-25, 2016.

[5] N. Thombare, U. Jha, S. Mishra, and M. Z. Siddiqui, "Guar gum as a promising starting material for diverse applications: A review," International Journal of Biological Macromolecules, vol. 88, pp. 361-372, 2016.

[6] K. Ofori-Kwakye, Y. Asantewaa, and S. L. Kipo, "Physicochemical and binding properties of cashew tree gum in metronidazole tablet formulations," International Journal of Pharmacy and Pharmaceutical Sciences, vol. 2, no. 4, pp. 105-109, 2010.

[7] A. M. S. Maia, H. V. M. Silva, P. S. Curti, and R. C. Balaban, "Study of the reaction of grafting acrylamide onto xanthan gum," Carbohydrate Polymers, vol. 90, no. 2, pp. 778-783, 2012.

[8] P. V. Quelemes, A. R. Araujo, A. Placido et al., "Quaternized cashew gum: an anti-staphylococcal and biocompatible cationic polymer for biotechnological applications," Carbohydrate Polymers, vol. 157, pp. 567-575, 2017.

[9] R. M. A. Daoub, A. H. Elmubarak, M. Misran, E. A. Hassan, and M. E. Osman, "Characterization and functional properties of some natural Acacia gums," Journal of the Saudi Society of Agricultural Sciences, 2016.

[10] L. Bai, S. Huan, Z. Li, and D. J. McClements, "Comparison of emulsifying properties of food-grade polysaccharides in oil-inwater emulsions: gum arabic, beet pectin, and corn fiber gum," Food Hydrocolloids, vol. 66, pp. 144-153, 2017.

[11] S. Agnello, L. Gasperini, J. F. Mano et al., "Synthesis, mechanical and thermal rheological properties of new gellan gum derivatives," International Journal of Biological Macromolecules, vol. 98, pp. 646-653, 2017.

[12] A. Rezaei, A. Nasirpour, and H. Tavanai, "Fractionation and some physicochemical properties of almond gum (Amygdalus communis L.) exudates," Food Hydrocolloids, vol. 60, pp. 461469, 2016.

[13] J. B. Lowry, Trees for Wood and Animal Production in Northern Australia, Rural Industries Research and Development Corporation. Indooroopilly, Queensland, 2008.

[14] L. Pachuau and B. Mazumder, "Evaluation of Albizia procera gum as compression coating material for colonic delivery of budesonide," International Journal of Biological Macromolecules, vol. 61, pp. 333-339, 2013.

[15] A. R. Dabhade, N. U. Mokashe, and U. K. Patil, "Purification, characterization, and antimicrobial activity of nontoxic trypsin inhibitor from Albizia amara Boiv.," Process Biochemistry, vol. 51, no. 5, pp. 659-674, 2016.

[16] I. F. Adebesin, A. J. Akindele, and O. O. Adeyemi, "Evaluation of neuropharmacological effects of aqueous leaf extract of Albizia glaberrima (Leguminosae) in mice," Journal of Ethnopharmacology, vol. 160, pp. 101-108, 2015.

[17] Z. P. Mahlangu, F. S. Botha, E. Madoroba, K. Chokoe, and E. E. Elgorashi, "Antimicrobial activity of Albizia gummifera leaf extracts against four Salmonella serovars," South African Journal of Botany, vol. 108, pp. 132-136, 2017.

[18] O. P. Noté, S. A. Azouaou, L. Simo et al., "Phenotype-specific apoptosis induced by three new triterpenoid saponins from Albizia glaberrima (Schumach. \& Thonn.) Benth," Fitoterapia, vol. 109, pp. 80-86, 2016.

[19] V. S. T., L. J. K. Henry, K. Narra, P. Lalduhsanga, and R. Kandasamy, "Design and development of Albizia stipulata gum based controlled-release matrix tablets in cancer therapeutics," International Journal of Biological Macromolecules, vol. 92, pp. 972980, 2016.

[20] T. A. Afolabi, "Synthesis and physicochemical properties of carboxymethylated bambara groundnut (Voandzeia subterranean) starch," International Journal of Food Science and Technology, vol. 47, no. 3, pp. 445-451, 2012.

[21] B. O. Okezie and A. Bello, "Physicochemical and functional properties of winged bean flour and isolate compared with soy isolate," Journal of Food Science, vol. 53, no. 2, pp. 450-454, 1988.

[22] P. Rani, G. Sen, S. Mishra, and U. Jha, "Microwave assisted synthesis of polyacrylamide grafted gum ghatti and its application as flocculant," Carbohydrate Polymers, vol. 89, no. 1, pp. 275-281, 2012.

[23] FAO., "Specification for identity and purity of certain foodadditives," Food and Nutrition Paper No. 49, Rome, 1990.

[24] R. C. Rowe, P. J. Sheskey, and S. C. Owen, Hand book of Pharmaceutical Excipients, Pharmaceutical Press, London, Fifth edition edition, 2006.

[25] G. S. Mhinzi, "Properties of gum exudates from selected Albizia species from Tanzania," Food Chemistry, vol. 77, no. 3, pp. 301304, 2002.

[26] M. Faisal, P. P. Singh, and R. Irchaiya, "Review on Albizia Lebebeck: a potent herbal drug," International Research Journal of Pharmacy, pp. 5-11, 3.

[27] M. Bashir and S. Haripriya, "Assessment of physical and structural characteristics of almond gum," International Journal of Biological Macromolecules, vol. 93, pp. 476-482, 2016.

[28] E. Dickinson, "Emulsifying properties of selected gums," Food Hydrocolloid, vol. 17, p. 25, 2003.

[29] K. S. Chee, P. A. Williams, S. W. Cui, and Q. Wang, "Characterization of the surface-active components of sugar beet pectin and the hydrodynamic thickness of the adsorbed pectin layer," Journal of Agricultural and Food Chemistry, vol. 56, no. 17, pp. 8111-8120, 2008.

[30] V. S. Meka, S. R. Nali, A. S. Songa, and V. R. M. Kolapalli, "Characterization and in vitro drug release studies of a natural polysaccharide Terminalia catappa gum (Badam gum)," AAPS PharmSciTech, vol. 13, no. 4, pp. 1451-1464, 2012.

[31] P. F. Builders, C. C. Mbah, and A. A. Attama, "Intrinsic and Functional Properties of a Gelling Gum from Dioclea reflexa: a potential pharmaceutical excipient," British Journal of Pharmaceutical Research, vol. 2, no. 1, pp. 50-68, 2012.

[32] E. I. Nep and B. R. Conway, "Physicochemical characterization of grewia polysaccharide gum: Effect of drying method," Carbohydrate Polymers, vol. 84, no. 1, pp. 446-453, 2011.

[33] R. L. Carr, "Evaluating flow properties of solids," Chemical Engineering Journal, vol. 72, pp. 163-168, 1965.

[34] W. Cui and G. Mazza, "Physicochemical characteristics of flaxseed gum," Food Research International, vol. 29, no. 3-4, pp. 397402, 1996.

[35] R. C. M. De Paula, S. A. Santana, and J. F. Rodrigues, "Composition and rheological properties of Albizia lebbeck gum exudate," Carbohydrate Polymers, vol. 44, no. 2, pp. 133-139, 2001.

[36] G. S. Mhinzi, "Intra-species variation of the properties of gum exudates from Acacia senegal var. senegal and Acacia seyal var. fistula from Tanzania," Chemical Society of Ethiopia, vol. 17, pp. 67-74, 2003.

[37] R. P. Singh, T. Tripathy, G. P. Karmakar et al., "Novel biodegradable flocculants based on polysaccharides," Current Science, vol. 78, no. 7, p. 10, 2000. 

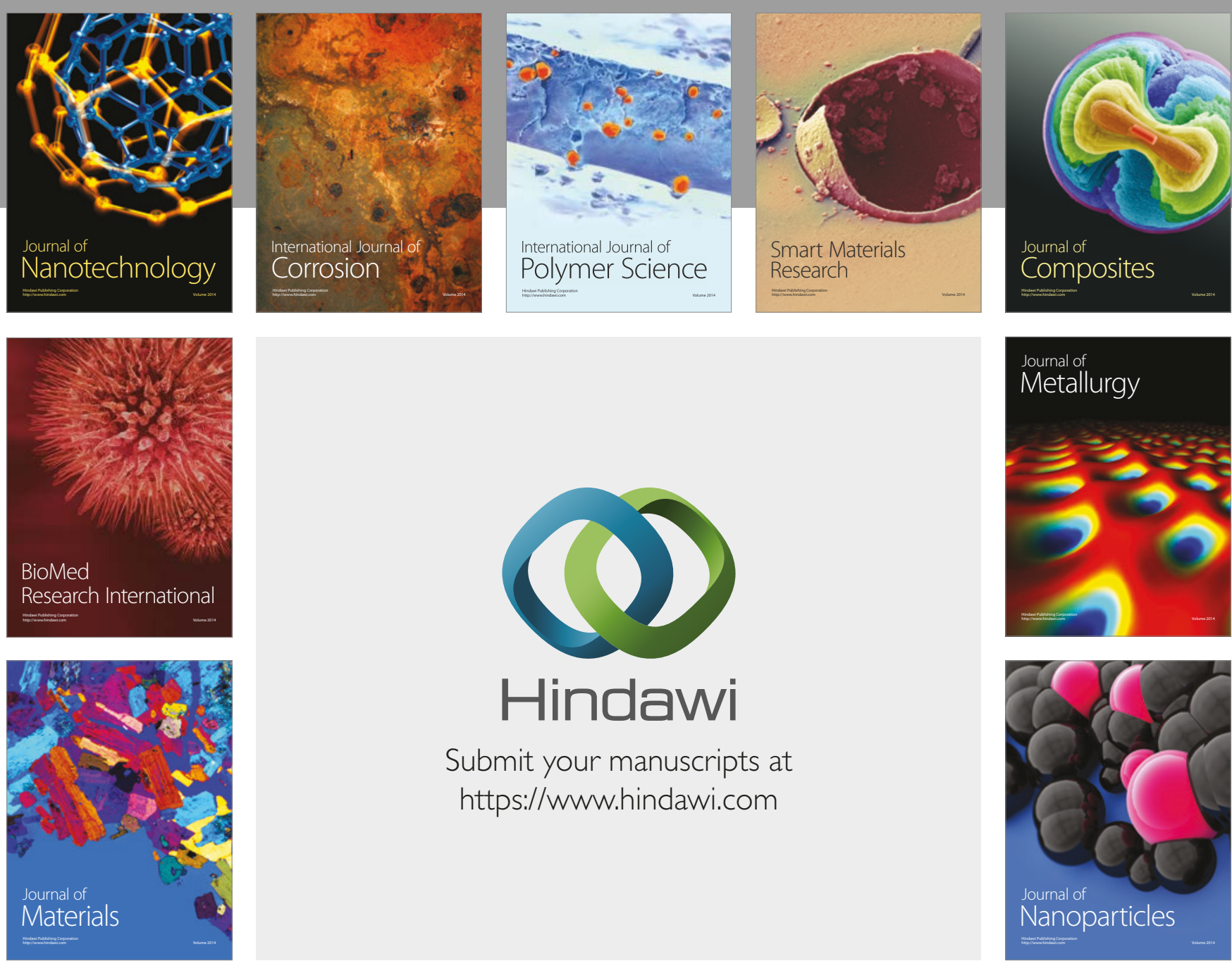

\section{Hindawi}

Submit your manuscripts at

https://www.hindawi.com
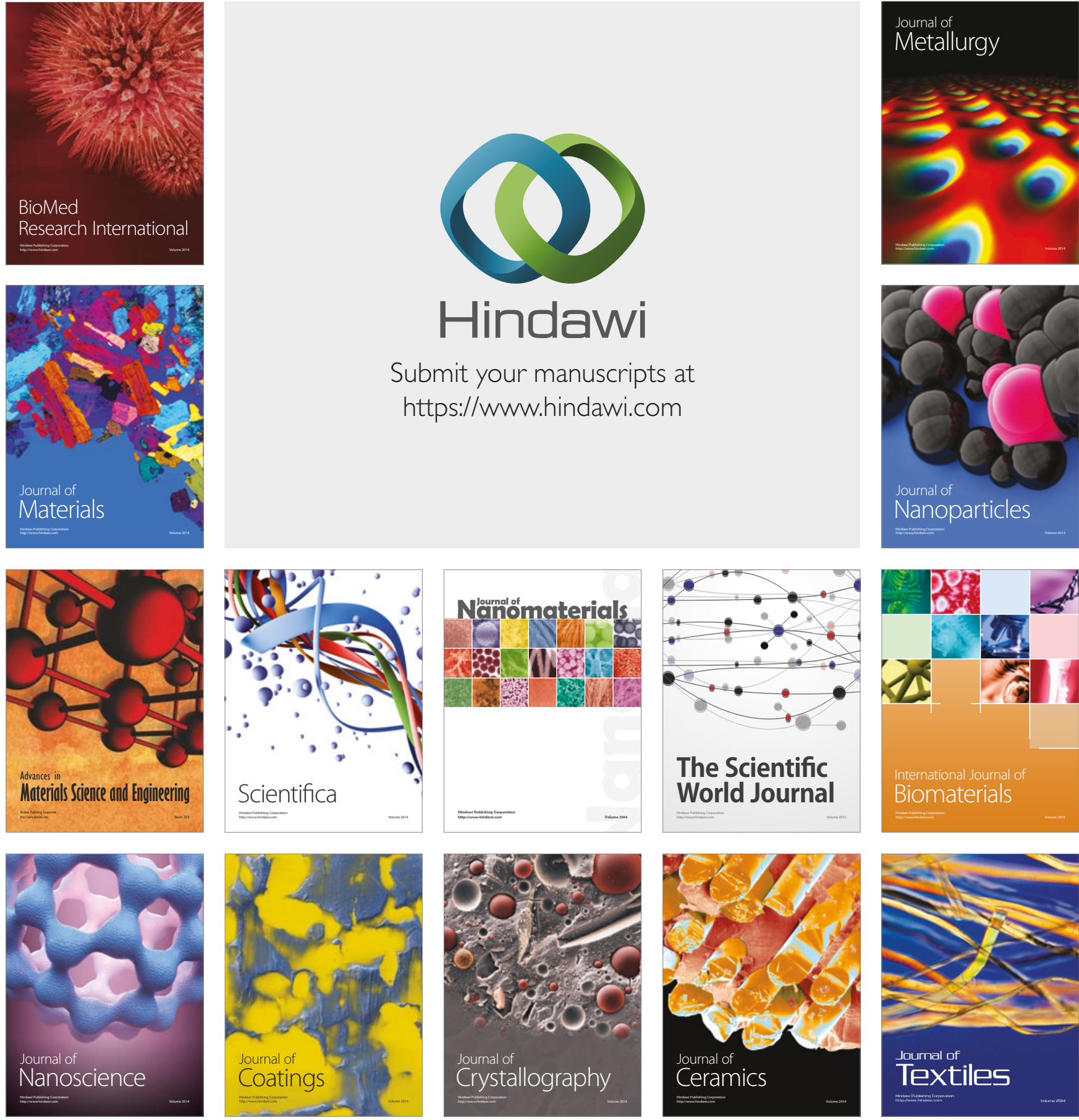

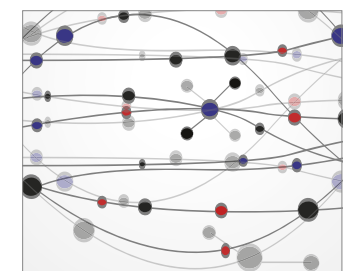

The Scientific World Journal
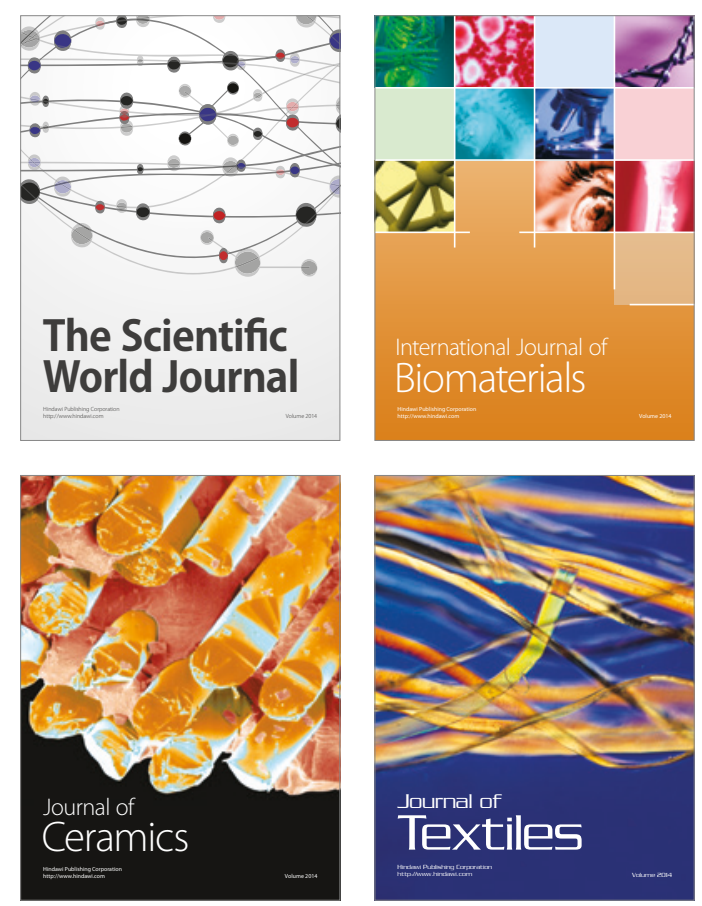